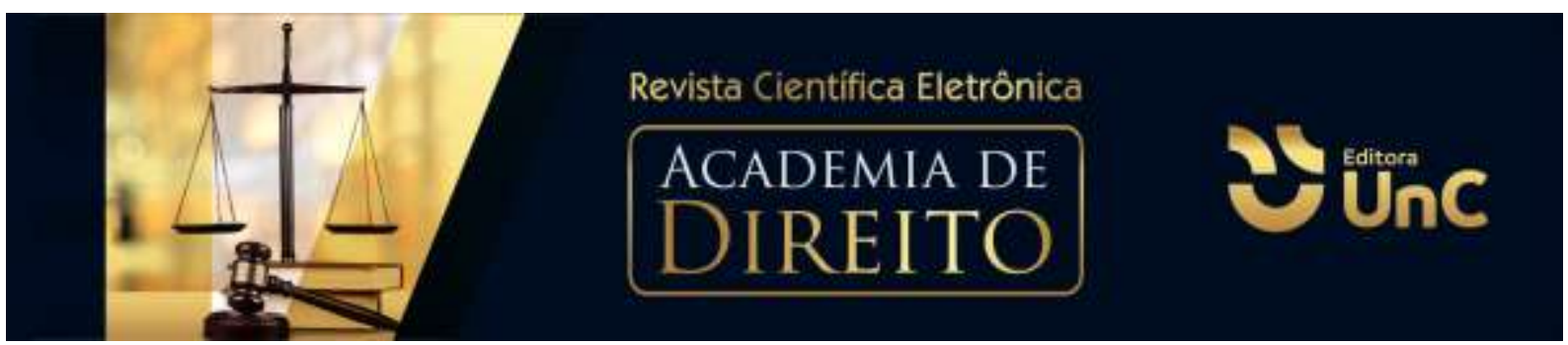

\title{
O COMBATE AO ABSENTEÍSMO DISCENTE PROMOVIDO PELO MINISTÉRIO PÚBLICO NA COMARCA DE PAPANDUVA NO ANO DE 2019
}

\section{THE FIGHT AGAINST DISCENT ABSENTISM PROMOTED BY THE PUBLIC MINISTRY IN THE COMMAND OF PAPANDUVA IN 2019}

\author{
David Sidney da Silva ${ }^{1}$ \\ Cilmara Corrêa de Lima Fante ${ }^{2}$
}

\begin{abstract}
RESUMO
O presente estudo teve como propósito investigar como o Ministério Público combateu o problema do absenteísmo discente na Comarca de Papanduva, durante o ano de 2019. Para tanto, preliminarmente abordou-se o direito à educação, fundamental e essencial para o desenvolvimento pessoal, econômico e social, juntamente com as diretrizes e tutelas contidas na Constituição Federal e nas Leis 8.069/90 e 9.394/96. $\mathrm{Na}$ sequencia, analisou-se a estrutura e atribuições do Ministério Público, seu papel como guardião do direito à educação e o funcionamento do programa APOIA, principal sistema utilizado pelo parquet em casos envolvendo absenteísmo escolar. Após, utilizou-se de dados estatísticos do APOIA relacionados à Comarca de Papanduva, com informações sobre os métodos, motivações e taxa de êxito, culminando em melhor perspectiva acerca da efetividade do programa e da atuação do Ministério Público. A metodologia utilizada foi o método indutivo, através da análise qualitativa e quantitativa, com pesquisa bibliográfica, levantamento e análise de dados estatísticos.
\end{abstract}

Palavras-Chave: Educação. Ministério Público. Programa APOIA

\section{ABSTRACT}

The purpose of this study was to investigate how the Public Prosecutor's Office tackled the problem of student absenteeism in the Papanduva County, during 2019. To do so, the right to education, which is fundamental and essential for personal, economic and social, together with the guidelines and tutelage contained in the Federal Constitution and Laws 8.069 / 90 and 9.394 / 96. Then, the structure and attributions of the Public Ministry, its role as guardian of the right to education and the functioning of the APOIA

\footnotetext{
${ }^{1}$ Graduando em Direito, Universidade do Contestado - UnC. Canoinhas. Santa Catarina. Brasil. Email: david ss 201@hotmail.com

${ }^{2} A d v o g a d a$, mestre em Desenvolvimento Regional pela Universidade do Contestado. Professora no curso de Direito da Universidade do Contestado. Santa Catarina. Brasil. E-mail: cilmarafante@unc.br
}

Acad. Dir. (ISSNe: Em processo de criação) 
program, the main system used by parquet in cases involving school absenteeism, were analyzed. Afterwards, APOIA statistical data related to the Papanduva County was used, with information on the methods, motivations and success rate, culminating in a better perspective on the effectiveness of the program and the performance of the Public Ministry. The methodology used was the inductive method, through qualitative and quantitative analysis, with bibliographic research, survey and analysis of statistical data.

Keywords: Education. Public Ministry. APOIA program.

\section{INTRODUÇÃO}

O estudo em tela foi elaborado com o objetivo de aferir a atuação do Ministério Público durante o ano de 2019, na Comarca de Papanduva, em específico acerca das atitudes tomadas no combate ao absenteísmo discente.

Ao levantar o objeto do estudo em tela, exsurgem como pontos principais, a serem preliminarmente analisados para melhor contextualização e entendimento dos resultados, o direito à educação e legislação correlata, bem como a instituição Ministério Público e os mecanismos utilizados por ela para a proteção deste direito. Após, vislumbra-se o absenteísmo discente como fator bloqueador da efetiva fruição do direito em comento e, utilizando como amostra dados da Comarca de Papanduva referentes ao ano de 2019, coteja-se a materialização dos preceitos anteriormente levantados.

Nesta toada, primeiramente analisa-se a educação como mecanismo estrutural e transformador da sociedade, o qual constitui um direito fundamental considerado como de segunda geração (direitos sociais que exigem prestação e atuação do Estado), determinante no desenvolvimento pessoal, social e econômico. Sedimentado tal conceito, é observada a legislação pátria a fim de apurar quais são os principais dispositivos que tutelam o direito à educação.

Ato contínuo examina-se a instituição Ministério Público, sua organização, principais funções e atuação, em especial em casos envolvendo a ausência escolar das crianças e adolescentes. Neste ponto, conhecendo o programa Aviso Por Infrequência de Aluno (APOIA) como notória ferramenta do parquet catarinense, verifica-se o funcionamento do programa, os órgãos envolvidos e a sistemática 
utilizada, culminando no levantamento e análise dos dados estatísticos relativos à Comarca de Papanduva no ano de 2019.

Investigados tais pontos, a discussão e equação das variáveis obtidas possibilita-se a obtenção de resultados que demonstram como ocorreu a atuação da instituição no contexto levantado, as medidas empreendidas pelo órgão, principais motivos que conduzem os discentes à infrequência ou evasão escolar e, finalmente, a taxa de sucesso do programa APOIA na promoção do retorno dos estudantes aos estudos. Assim, possível vislumbrar, em paralelo, a eficácia do programa e da atuação do órgão, assim como adaptações e melhorias possíveis para potencializar o desempenho e aumentar a taxa de êxito.

Foi utilizado o método indutivo na presente pesquisa, através de análise qualitativa e quantitativa. Os materiais de pesquisa utilizados foram predominantemente bibliográficos, a partir da seleção e estudo de obras literárias e escritos acerca do assunto, contando também com dados estatísticos do Programa APOIA, referente ao Município de Papanduva, com acesso autorizado pelo Ministério Público de Santa Catarina.

\section{A EDUCAÇÃO COMO DIREITO FUNDAMENTAL}

Os direitos fundamentais englobam os pressupostos necessários para a existência de uma sociedade propícia à garantia da dignidade da pessoa humana e de um estado democrático de direito.

Conforme discorre Flávia Bahia (2017), estes direitos compreendem a proteção e promoção de condições fundamentais para uma vida adequada, com igualdade, independência possibilidade de desenvolvimento dos potenciais e vontades individuais.

Além de direitos subjetivos, os direitos fundamentais são elementos basilares da ordem constitucional objetiva. Como direitos subjetivos, outorgam aos titulares a possibilidade de impor seus interesses em face dos órgãos obrigados. Como elemento fundamental da ordem constitucional objetiva, formam a base do ordenamento jurídico de um Estado Democrático (MENDES, 1999). 
Doutrinariamente, divide-se os direitos fundamentais em dimensões, tratadas por alguns autores como gerações, compreendendo diferentes aspectos de limitações e prestações do Estado, as quais são relacionadas à evolução do constitucionalismo.

Primeiro, houve uma limitação do poder de Estado, com a afirmação dos direitos individuais, políticos e civis. Posteriormente, exigiu-se o dever de agir do Estado, com a prestação e garantia de direitos sociais, econômicos e culturais. Por último há o amadurecimento de novas exigências, ligadas à determinados grupos ou categorias, relacionados à convivência harmônica em sociedade (direitos relacionados à fraternidade e solidariedade), sendo que alguns autores modernos já defendem a existência de novas fases (GORCZEVSKI, 2009).

A segunda dimensão dos direitos fundamentais destaca-se pela necessidade de postura inversa da exigida do Estado anteriormente, ou seja, na segunda dimensão é requerida uma atividade do Estado em relação às necessidades.

É dizer, diferente das liberdades negativas, que exigiam do Estado mais autonomia em relação aos direitos políticos e civis, os direitos da segunda geração outorgam o direito de exigir, seja do Estado, de grupos sociais ou demais indivíduos, uma atitude, prestação e obrigação de cunho positivo, seja dar ou fazer (CONCEIÇÃO, 2016).

Dentre diversos direitos sociais considerados como de segunda geração, destaca-se a educação como essencial para a estrutura e desenvolvimento dos demais direitos fundamentais existentes.

Isto devido a sua natureza basilar, visto que é através da educação que são desenvolvidos, compreendidos e fixados os valores e princípios que nortearão a vida das pessoas. Este é o principal motivo de sua relevância, seu papel instrumental que permite a implementação de fato dos demais direitos, conforme destaca Maciel et al. (2018).

O desenvolvimento do indivíduo, no âmbito pessoal e social potencializa-se através da educação. Consequentemente, os reflexos de uma educação de qualidade permeiam dentre os mais variados eixos de uma nação, seja no âmbito familiar, econômico ou criminal. Exemplo disto é o fato de que a educação é um dos três fatores utilizados para cálculo do Índice de Desenvolvimento Humano (IDH) de uma região, juntamente à longevidade e à renda. 
No aspecto econômico, por sua vez, a educação repercute no nível de capacitação e consequentemente na produtividade.

Neste diapasão é o entendimento de Dimenstein (2005), segundo o qual educação não é apenas uma questão de cidadania. O nível de instrução do trabalhador tem relação direta com a produtividade e, portanto, com a riqueza material de um país.

A educação tem papel de oferecer condições mínimas para a inserção do indivíduo no mercado de trabalho, tendo em vista que com certo nível de educação, terá melhores condições de competição (BARCELOS, 2002). Logo, vislumbra-se sua importância para a garantia de igualdade.

Considerando o caráter fundamental do direito em comento, a legislação brasileira possui dispositivos voltados à sua garantia, enraizados desde a Carta Magna à legislação esparsa.

A Constituição da República Federativa do Brasil (CRFB), promulgada em 5 de outubro de 1988, em seu artigo $6^{\circ}$, elenca os direitos sociais, sendo a educação o primeiro referido no dispositivo em comento.

No decorrer do texto constitucional, o constituinte originário dedicou-se a positivar diversas diretrizes e garantias, a fim de assegurar tal direito.

O artigo 205 da carta em apreço discorre a educação como direito de todos, dever do Estado e da Família, que deverá visar o desenvolvimento da pessoa e prepara-la para o futuro, no âmbito social, laboral e pessoal (BRASIL, 1988).

Neste ponto, o Estado é incumbido de diversos deveres (CONCEIÇÃO, 2016), dentre eles a garantia direcionada às diferentes necessidades - como atendimento educacional especializado à portadores de deficiência - e fases do desenvolvimento das crianças, desde a educação infantil, básica e obrigatória a níveis mais elevados de ensino.

Há responsabilidade comum entre os entes federativos em relação à organização dos regimes de ensino, o que deverá ocorrer em colaboração, conforme preceitua o artigo $211^{3}$ da CRFB.

Acerca desta competência, complementa PADILHA (2018) que a CRFB compromete todos os entes ao dispor que é competência administrativa comum da

\footnotetext{
${ }^{3}$ Art. 211. A União, os Estados, o Distrito Federal e os Municípios organizarão em regime de colaboração seus sistemas de ensino. (BRASIL, 1988).
} 
União, Estado, Distrito Federal e Município proporcionar os meios de acesso à cultura, à educação e à ciência (artigo 23, $\mathrm{V}$ da CRFB).

O financiamento da educação pode ocorrer da forma privada, com prestações individuais, e pública. Os recursos do financiamento público são oriundos da arrecadação, principalmente de forma impositiva pelo Estado, e viabiliza a formulação e implementação de políticas públicas (CASTRO, 2007). Conforme o artigo 212 da CRFB, parte da receita resultante de impostos, compreendida a proveniente de transferências, sendo ao menos dezoito por cento pela União, e vinte e cinco por cento pelos Estados, Distrito Federal e Municípios, deverá ser aplica anualmente à manutenção e desenvolvimento da educação.

Salienta-se, ademais, que o dever em relação à garantia da educação à criança e ao adolescente não é apenas conferido ao Estado, cabendo tal proteção ser exercida com prioridade também pela sociedade e pela família, conforme preceitua o artigo 227 da CRFB ${ }^{4}$.

De acordo com Costa (2006), se a família demonstrar curiosidade em relação ao que acontece em sala de aula e reforçarem a importância do que está sendo aprendido, estarão contribuindo para o sucesso da aprendizagem.

Amparando as normas constitucionais relacionadas à educação, dando concretude e desenvolvendo os ideais da Lei Maior, destacam-se o Estatuto da Criança e do Adolescente, Lei n. 8.069/90 e a Lei n. 9.394/96 conhecida como Lei de Diretrizes e Bases da Educação (LDB).

Em simetria às diretrizes protetivas consagradas na Constituição Federal o Estatuto da Criança e do Adolescente (ECA) sedimenta e instrumentaliza as garantias e direitos das crianças e adolescentes, sendo a proteção integral deles seu cerne, como expressa logo artigo $1^{\circ}$ do estatuto ${ }^{5}$.

A proteção integral e o melhor interesse da criança e do adolescente são princípios norteadores mais do que essenciais à interpretação da norma, como bem discorre Ishida (2015).

\footnotetext{
${ }^{4}$ Art. 227. É dever da família, da sociedade e do Estado assegurar à criança, ao adolescente e ao jovem, com absoluta prioridade, o direito à vida, à saúde, à alimentação, à educação, ao lazer, à profissionalização, à cultura, à dignidade, ao respeito, à liberdade e à convivência familiar e comunitária, além de colocá-los a salvo de toda forma de negligência, discriminação, exploração, violência, crueldade e opressão. (BRASIL, 1988).

${ }^{5}$ Art. $1^{\circ}$ Esta Lei dispõe sobre a proteção integral à criança e ao adolescente.
} 
O ECA trata de matérias diversas relacionadas à criança e ao adolescente, tais como tutela, guarda, atos infracionais e medidas socioeducativas, políticas e entidades de atendimentos, medidas protetivas, medidas aplicáveis aos pais ou responsáveis, bem como prevê o Conselho Tutelar e seu papel na defesa dos direitos das crianças e adolescentes, além de dispor acerca da Justiça da Infância e da Juventude. O estatuto, portanto, explicitou melhor cada um dos direitos da criança e do adolescente além dos princípios que devem nortear as políticas de atendimento (CRAIDY; KAERCHER, 2011).

Harmônico à Constituição Federal, o estatuto dispõe, em seu artigo 53, que a criança e o adolescente têm direito à educação, visando ao pleno desenvolvimento de sua pessoa, preparo para o exercício da cidadania e qualificação para o trabalho.

Para garantir isto, a lei assegura, através do dispositivo supracitado, a igualdade de condições para o acesso e permanência na escola, o direito de ser respeitado por seus educadores, contestar critérios avaliativos, organizar e participar em entidades estudantis e ter acesso à escola pública e gratuita, de preferência o mais perto possível de sua residência e juntamente com irmãos que estejam na mesma etapa ou ciclo (BRASIL, 1988).

Havendo ameaça ou violação de direitos da criança ou do adolescente, seja por ação ou omissão do Estado, falta, omissão ou abuso pelos pais ou responsáveis, ou ainda decorrente de sua própria conduta, dispõe o artigo 98 do ECA que serão cabíveis medidas de proteção. Estas medidas são aplicadas por autoridades que possuem poderes especiais sempre que crianças ou adolescentes tiverem seus direitos ameaçados ou violados (SÊDA, 1990, apud, LIBERATI, 2010).

Como uma das medidas específicas de proteção elencadas no estatuto (artigo 101, inciso III), voltada à garantia de ingresso e permanência em instituição de ensino, está a medida de matrícula e frequência obrigatórias em estabelecimento oficial de ensino fundamental.

Nesta toada, o ECA também prevê, conforme preceitua o artigo 129, inciso $\mathrm{V}$, medidas aplicáveis aos pais ou responsáveis, dentre as quais possível citar a obrigação de matricular o filho ou pupilo e acompanhar sua frequência escolar.

Havendo desídia dos pais em ou responsáveis em relação à obrigação de zelar pela educação dos filhos, o artigo 249 do referido diploma normativo dispõe a possibilidade de representação por infração administrativa decorrente do 
descumprimento dos deveres inerentes ao poder familiar. Acerca destas infrações, Maciel, et al (2018) destaca que são tuteladas com sanções de cunho administrativo, restritivos de direitos, mas não de liberdade.

Por sua vez, a LDB fixa normas de organização, funcionamento e gestão de ensino, sendo consolidando e dando forma aos preceitos constitucionais relacionados à educação.

As disposições acerca da organização da educação, divisão de competências entre a União, o Estado os Municípios, bem como o regime de colaboração entre eles, conforme disposto na CRFB, é reafirmado na LDB, conforme extrai-se do Título IV.

A educação, de acordo com a LDB (artigo 21), é dividida em básica e superior, sendo que a educação básica é formada pela educação infantil, ensino fundamental e ensino médio.

Em relação à educação infantil, será oferecida em creches ou entidades equivalentes, para crianças de até três anos de idade e em pré-escolas para as crianças de quatro a cinco anos de idade, conforme dispõe o artigo 30 da lei em comento, com redação dada pela Lei n. 12.796 de 4 de abril 2013.

De acordo com os artigos 32 e 35 da LDB, o ensino fundamental obrigatório, compreende nove anos de educação, a partir dos seis anos de idade. O ensino médio, por sua vez, é a etapa final da educação básica, com duração mínima de três anos. A obrigatoriedade do ensino fundamental pode ser desdobrada em dois momentos, conforme comenta Liberati (2004), notadamente a obrigação do Poder Público e dos genitores.

Reiterando a disposição do artigo 208, inciso I, da Constituição Federal, a LDB discorre, em seus artigos 37 e 38, acerca da Educação de Jovens e Adultos (EJA), destinada àqueles que não tiveram acesso ou continuidade de estudos nos ensinos fundamental e médio na idade própria.

A educação especial também é prevista na $\mathrm{LDB}^{6}$, que traz diretrizes acerca do atendimento e ensino diferenciado à alunos portadores de necessidades especiais. Trata-se, portanto, de uma garantia de ensino de qualidade, adaptável e flexível às necessidades especiais.

\footnotetext{
${ }^{6}$ Art. 58. Entende-se por educação especial, para os efeitos desta Lei, a modalidade de educação escolar oferecida preferencialmente na rede regular de ensino, para educandos com deficiência, transtornos globais do desenvolvimento e altas habilidades ou superdotação.
} 
Para garantir a eficácia e aplicabilidade das normas constitucionais e infraconstitucionais destacadas alhures, exsurge o Ministério Público, incumbido da defesa da ordem jurídica, do regime democrático e dos interesses sociais e individuais indisponíveis.

\section{O MINISTÉRIO PÚBLICO, O PROGRAMA APOIA E O ABSENTEÍSMO DISCENTE}

A CRFB consagrou o Ministério Público como instituição incumbida da proteção da ordem jurídica, do regime democrático e dos interesses sociais e individuais indisponíveis ${ }^{7}$, regrando sua estrutura, abrangência e atribuições, como função essencial à Justiça (Título IV, Capítulo IV).

A tutela destes interesses constitui a função típica do Ministério Público consagrada na Constituição Federal de 1988, no artigo 127, supracitado, bem como no artigo $1^{\circ}$ da Lei n. 8.625 de 12 de fevereiro de 1993, conhecida como Lei Orgânica Nacional do Ministério Público (LONMP).

Os direitos de terceira geração, interesses sociais difusos, coletivos e homogêneos também são tutelados pelo MP. Há definição e distinção legal entre eles no artigo 81, incisos I, II e III da Lei n. 8.078 de 1990, conhecida como Código do Consumidor (CDC). $O$ referido texto legislativo dispõe que são interesses ou direitos difusos, aqueles transindividuais, de natureza indivisível, de que sejam titulares pessoas indeterminadas e ligadas por circunstâncias de fato.

Os direitos coletivos são os transindividuais, de natureza indivisível de que seja titular grupo, categoria ou classe de pessoas ligadas entre si ou com a parte contrária por uma relação jurídica base. Já os direitos individuais homogêneos constituem os decorrentes de origem comum.

$\mathrm{Na}$ proteção dos interesses coletivos, destaca-se primeiramente que o Ministério Público possui legitimidade para propor a ação civil pública (ACP) (artigo 129, III da CRFB), no intuito de proteger o patrimônio público e social, do meio ambiente e de outros interesses difusos e coletivos.

\footnotetext{
${ }^{7}$ Art. 127. O Ministério Público é instituição permanente, essencial à função jurisdicional do Estado, incumbindo-lhe a defesa da ordem jurídica, do regime democrático e dos interesses sociais e individuais indisponíveis (BRASIL, 1988).
} 
Sintetizando as atribuições conferidas constitucionalmente ao MP através do artigo 129, além da tutela dos direitos e interesses individuais indisponíveis, explana Martins Junior (2015) que o órgão também é agente da ação penal pública e fiscal da lei, habilitado para intervir e manifestar pareceres.

A LOMP complementa, em seu artigo 25 , as funções de exercer a fiscalização dos estabelecimentos prisionais e dos que abriguem idosos, menores, incapazes ou pessoas portadoras de deficiência; deliberar sobre a participação em organismos estatais de defesa do meio ambiente, neste compreendido o do trabalho, do consumidor, de política penal e penitenciária e outros afetos à sua área de atuação; ingressar em juízo, de ofício, para responsabilizar os gestores do dinheiro público condenados por tribunais e conselhos de contas (BRASIL, 1993).

Acerca do rol supramencionado, Mazzilli (2005), destaca que inexiste taxatividade, sendo que além das hipóteses expressamente previstas em diversas leis, qualquer outro interesse difuso, coletivo ou individual homogêneo pode em tese ser defendido em juízo pelo MP.

A Lei n. 13.105 de 2015, que institui o Código de Processo Civil Brasileiro (CPC), determina que o MP atuará como fiscal da ordem jurídica nos casos previstos pela CRFB, bem como nos processos que envolvam interesse público ou social, interesse de incapaz ou litígios coletivos pela posse de terra rural ou urbana.

A educação, como direito fundamental, que envolve interesse público, social e de incapaz, é tutelada pelo MP, por decorrência dos dispositivos supracitados, havendo determinações e programas específicos da instituição, voltados à tutela do direito em comento, seja de forma preventiva ou repressiva.

Como principais ações desenvolvidas, destaca Nunes (2020) que cabe ao MP diagnosticar a situação educacional dos municípios e seus planos, elaborar planos de educação de acordo com as necessidades específicas, estabelecer canais de conversação e núcleos de articulação, zelar pela correta aplicação das verbas de financiamento da educação (para cumprimento do disposto no artigo 212 da CRFB $^{8}$ ), zelar pela regularidade no funcionamento dos Conselhos Municipais, bem como pela segurança nas instituições de ensino e prevenir a evasão escolar.

\footnotetext{
${ }^{8}$ Art. 212. A União aplicará, anualmente, nunca menos de dezoito, e os Estados, o Distrito Federal e os Municípios vinte e cinco por cento, no mínimo, da receita resultante de impostos, compreendida a proveniente de transferências, na manutenção e desenvolvimento do ensino.
} 
Para a consecução destes objetivos, como forma preventiva, o MP utiliza procedimentos investigativos, como o inquérito civil (Art. 25, IV da LONMP) e atua em conjunto com rede de proteção (que engloba as Instituições de Ensino, o Conselho Tutelar, e o MP) para identificar os casos e solucioná-los no âmbito extrajudicial, seja por meio de informação, palestras ou acompanhamento e auxílio às famílias. Tratase, portanto, de uma política pública direcionada ao tema. À título de complementação, insta gizar que política pública "pode ser considerada como o resultado das atividades dos atores públicos, devidamente investidos no poder público", conforme pontua Maria Goretti Dal Bosco (2007, p. 245).

Destaca-se como exemplo e expoente destas atividades, o programa APOIA (Aviso por Infrequência do Aluno). O programa, desenvolvido no ano de 2001 pelo Ministério Público de Santa Catarina, formula uma sistemática para potencializar a atuação conjunta dos órgãos da rede de proteção. O objetivo é promover a inserção ou reinserção da criança ou adolescente de 4 (quatro) a 17 (dezessete) anos na rede de ensino, e abrange escolas municipais, estaduais, públicas e privadas (SANTA CATARINA, Ministério Público, 2020).

Em que pese o nome do programa utilizar apenas o termo infrequência, o alvo das atividades do programa APOIA é o absenteísmo discente como um todo. É dizer, combate-se a ausência do aluno, seja infrequente ou totalmente evadido das atividades escolares.

O termo absenteísmo, embora mais utilizado na área da administração, também é utilizado na literatura educacional. O absenteísmo escolar, por sua vez, é entendido como a falta, a evasão, a ausência injustificada de comparecimento às aulas (REID, 1981 apud VASCONCELLOS; MATTOS, 2011).

No Brasil, conforme dados colacionados na mais recente Síntese de Indicadores Sociais do Instituto Brasileiro de Geografia e Estatística-IBGE (IBGE, 2019), em 2018 a taxa ajustada de frequência escolar líquida nos anos iniciais do ensino fundamental era de $96,1 \%$ e para os anos finais do ensino fundamental e ensino médio eram de $86,7 \%$ e $69,3 \%$, respectivamente.

Neste contexto, o estopim para o início das atividades do programa em comento ocorre com a falta do aluno por cinco dias seguidos ou sete dias durante o mês. Nestes casos, a Escola busca contato com a família do aluno para averiguar os motivos, os quais podem ser diversos, bem como promover orientação. Não havendo 
o retorno do aluno às aulas em uma semana, o caso é encaminhado ao Conselho Tutelar local, que irá averiguar os fatos buscando também uma solução, através de uma abordagem mais próxima da família, visitando os lares frequentemente. Transcorridos 15 dias, não havendo êxito, o caso será enviado ao Ministério Público. O órgão também promoverá diligências no intuito da solução que atenda ao melhor interesse da criança ou adolescente, buscando, primeiramente, acordo com as partes e solução conciliatória e extrajudicial para o deslinde do $\operatorname{caso}^{9}$ (SANTA CATARINA, Ministério Público, 2020).

O programa também conta com o Núcleo Intersetorial de Suporte ao APOIA NISA, que busca criar espaços intersetoriais e em rede para a elaboração e articulação de planos de atuação conjunta entre grupos municípios catarinenses.

Após efetuadas as atividades supracitadas, não havendo êxito em promover o retorno do estudante às aulas, o parquet atua de forma repressiva, vez que consolidada a ausência. Para tal, utiliza instrumentos como a denúncia pelo crime de abandono material, requerimento de aplicação medidas protetivas à criança e ao adolescente (art. 101 do ECA), bem como representação por infração administrativa decorrente do descumprimento dos deveres inerentes ao poder familiar (art. $249^{10}$ do $E C A$ ), institutos mencionados alhures.

Posto isto, tendo em vista o direito à educação como fundamental, tutelado pela legislação brasileira em diversos dispositivos, e protegido pela instituição do Ministério Público, no presente estudo será analisada a atuação do parquet no combate ao absenteísmo discente, em específico através do programa APOIA, utilizando como amostra dados da Comarca de Papanduva durante o ano de 2019.

\section{A ATUAÇÃO DO PARQUET NA COMARCA DE PAPANDUVA NO ANO DE 2019}

A abordagem metodológica utilizada no presente estudo é a quali-quantitativa. Para isto, foi requisitado dados numéricos ao Centro de Apoio Operacional da Infância

\footnotetext{
${ }^{9}$ (Síntese da sistemática exposta em material institucional, disponível em https://www.mpsc.mp.br/programas/programa-de-combate-a-evasao-escolar-apoia.)

${ }^{10}$ Art. 249. Descumprir, dolosa ou culposamente, os deveres inerentes ao poder familiar ou decorrente de tutela ou guarda, bem assim determinação da autoridade judiciária ou Conselho Tutelar: Pena - multa de três a vinte salários de referência, aplicando-se o dobro em caso de reincidência. (BRASIL, 1990)
} 
e Juventude do Ministério Público de Santa Catarina (CIJ/MPSC) e à $1^{\text {a }}$ Promotoria de Justiça de Papanduva, relativos ao programa APOIA na Comarca de Papanduva no ano de 2019, bem como demais estatísticas fornecidas pelo órgão.

Após, foi realizada análise e organização dos números e fatores contidos nos relatórios fornecidos. Desta forma, foram confeccionados tabelas e gráficos, bem como realizada análise percentual. Através desta sistemática, foi possível verificar os principais fatores envolvidos nos casos de absenteísmo discente, motivos e medidas adotadas, conforme resultados a seguir expostos.

A Comarca de Papanduva, situada na mesorregião norte de Santa Catarina, microrregião de Canoinhas, pertence à subseção de Joinville, circunscrição $28^{a}$ Mafra, é de entrância inicial e abrange os municípios de Papanduva e Monte Castelo (SANTA CATARINA, Tribunal de Justiça, 2020).

De acordo com o IBGE, a cidade de Papanduva possuía, em 2019, população estimada de 19.320 (dezenove mil trezentos e vinte) pessoas. Conforme a última pesquisa realizada pelo instituto, em 2010, o IDH era de 0,704 e a taxa de escolarização de 6 a 14 anos era de 98,1\%. O Índice de Desenvolvimento da Educação Básica - IDEB, mais recente, equacionado no ano de 2017, era de 7,0 para os anos iniciais e 5,0 para os anos finais na rede pública (IBGE, 2020).

Por sua vez, o município de Monte Castelo, em 2019, possuía população estimada de 8.275 (oito mil duzentos e setenta e cinco) pessoas, o IDH em 2010 era de 0,675, a taxa de escolarização de 6 a 14 anos era 98,4. O IDEB auferido no ano de 2017 era de 5,8 para os anos iniciais e 4,5 para os anos finais na rede pública (IBGE, 2020).

A atuação do Ministério Público de Santa Catarina na Comarca de Papanduva ocorre através de duas Promotorias sediadas no município de Papanduva. A $1^{\text {a }}$ Promotoria de Justiça da Comarca de Papanduva atua nas áreas cível, da família, Fazenda Pública, infância e juventude, moralidade administrativa, sucessões, consumidor, do controle de constitucionalidade, Terceiro Setor - Fundações, direitos humanos - cidadania, registros públicos, falência e procedimentos de habilitação de casamento. Já a $2^{\mathrm{a}}$ Promotoria de Justiça da Comarca atua na área criminal, juizado especial criminal, execução penal, ordem tributária, controle externo da atividade policial - Segurança Pública, meio Ambiente, juizado de violência doméstica e familiar contra a mulher (SANTA CATARINA, Ministério Público, 2020). 
Em relação ao combate ao absenteísmo discente, a atuação ocorre sobretudo através das atividades do sistema APOIA. Conforme dados dispostos pelo CIJ/MPSC, no ano de 2019 foram registrados 223 (duzentos e vinte e três) ocorrências no sistema APOIA online, principal plataforma de controle dos casos pela rede de proteção. Destas, 95 (noventa e cinco) ocorrências foram no município de Monte Castelo, registradas por 7 (sete) instituições de ensino diferentes e 128 (cento e vinte e oito) em Papanduva, registradas por 9 (nove) instituições diferentes.

Quanto ao período em que mais foram observados casos no ano em análise, denota-se que foram registrados mais casos no mês de maio e de agosto, conforme dados expressos no gráfico a seguir.

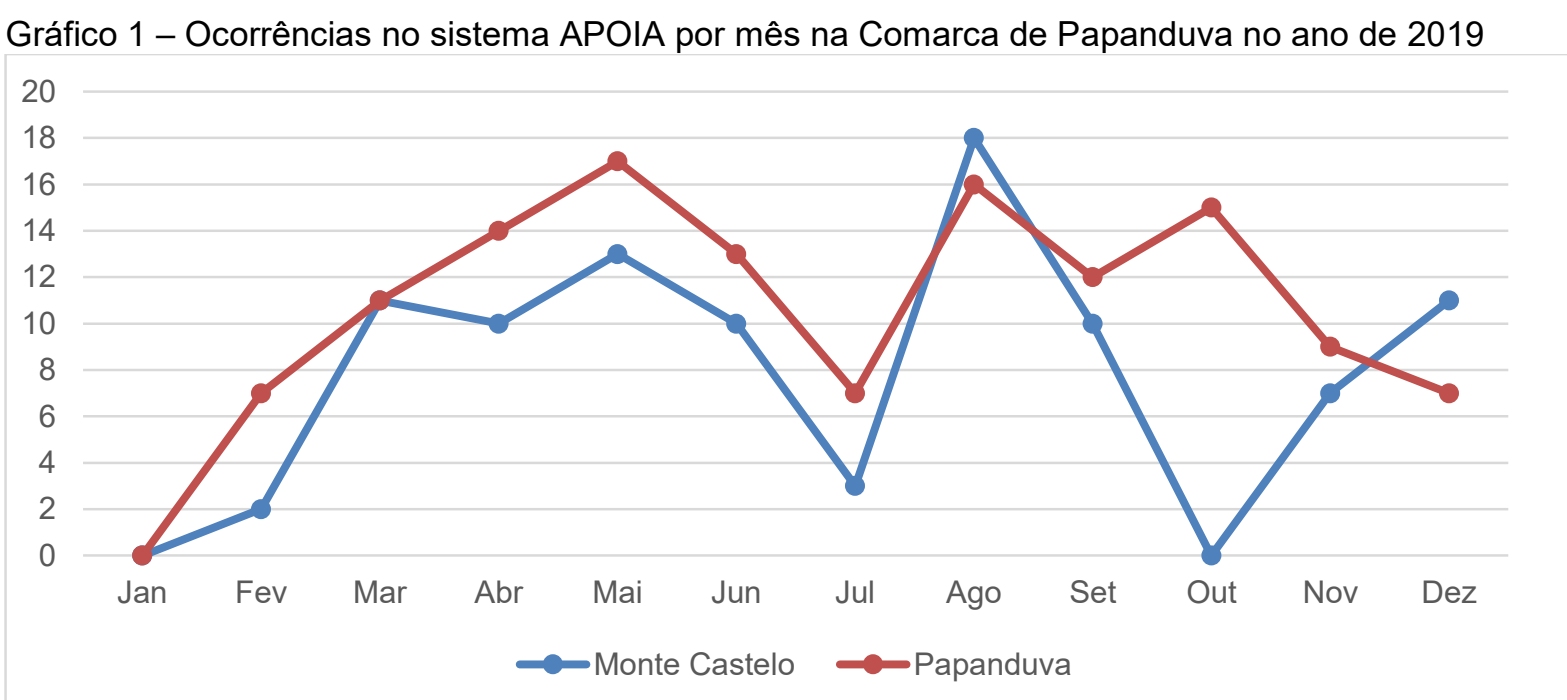

Fonte: Dados da pesquisa, 2019.

O sistema APOIA on-line classifica os principais motivos alegados para a infrequência/evasão, que servem como parâmetro indicativo da realidade social na região e auxiliam na organização do trabalho da rede de proteção para o retorno do discente aos estudos escolares.

Os motivos são cumulativos. Isto é, determinada ocorrência pode englobar mais de um motivo, e ser apontada mais de uma vez na ocorrência por órgãos diferentes, considerando o sistema progressivo do atendimento. Exemplifica-se em determinado caso em que a escola apontou problema com outro aluno, o que não foi vislumbrado pelo Conselho Tutelar, mas foi novamente suscitado pelo parquet. Logo, esta única ocorrência computou duas vezes o motivo. 
Salienta-se que nem todo caso passa pelos três órgãos. Por esta razão o número total de motivos alegados não se equaliza ao total de ocorrências, mas serve para indicar predominância de motivos em um quadro geral. Embora o total de ocorrências atendidas individualmente por cada órgão não terem sido disponibilizadas para pesquisa, foram apresentados principais motivos constatados pelo Ministério Público através do sistema APOIA, expostos a seguir.

$\mathrm{Na}$ cidade de Monte Castelo, os principais motivos para a infrequência ou evasão do discente constados pelo Ministério Público podem ser resumidas da seguinte maneira:

Gráfico 2 - Motivos para a ausência do discente constatados pelo MP na cidade de Monte Castelo
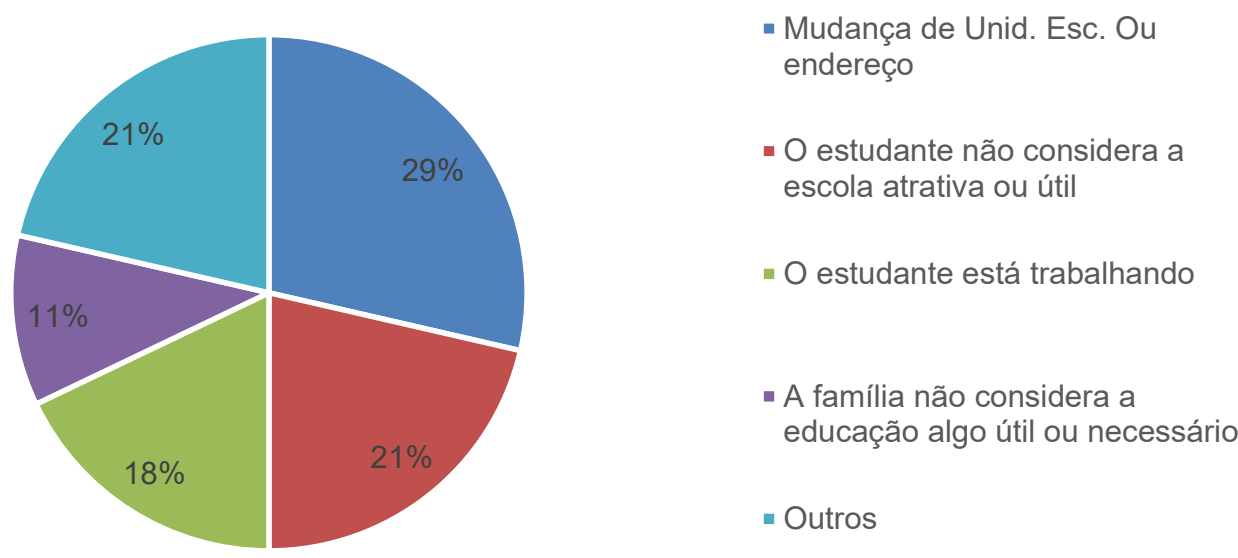

Fonte: Dados da pesquisa, 2019.

Por sua vez, a cidade de Papanduva apresentou os seguintes motivos números e: 
Gráfico 3 - Motivos para a ausência do discente constatados pelo MP na cidade de Papanduva

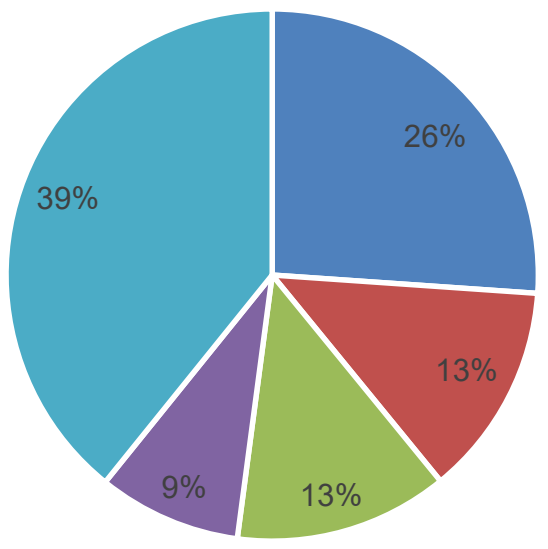

- O estudante não considera a escola atrativa ou útil

- O estudante está trabalhando

- Mudança de Unid. Esc. Ou endereço

- Tratamento de saúde

- Outros

Fonte: Dados da pesquisa, 2019.

De análise aos dados fornecidos, o principal motivo verificado para a ausência escolar é a resistência do próprio aluno, em que pese diversos casos mudança de unidade escolar ou endereço sem confirmação da continuidade dos estudos. Assim como verificado pelo parquet, conforme dados do sistema APOIA, as escolas de Monte Castelo apontaram que em $57,0 \%$ dos casos atendidos por elas foi verificado que o estudante não considera a escola atrativa e útil para a sua vida. Em consonância, o Conselho Tutelar verificou tal motivo em $51,2 \%$ dos casos atendidos pelo órgão. O mesmo panorama foi verificado na cidade de Papanduva, onde as escolas verificaram tal motivo em $62,8 \%$ dos casos e o Conselho Tutelar em $36,8 \%$ dos casos trabalhados.

O início de atividades laborais também constitui um dos principais motivos para a ausência do discente, sendo observado pelo Ministério Público em 18\% dos casos na cidade de Monte Castelo e em 13\% dos casos trabalhados na cidade de Papanduva durante o ano de 2019.

Acerca dos motivos observados em Monte Castelo, sobressai a informação de que foi constado, em $11 \%$ dos casos, que a família não considera a educação algo útil ou necessário, de forma totalmente contrária aos preceitos obrigacionais legais mencionados alhures.

Os motivos classificados como "outros" no gráfico 1 foram observados em menor proporção e abrangem os seguintes temas, distribuídos de forma aproximadamente homogênea: mora com namorado (a)/em união estável/casamento, 
distorção idade-série/ano frequentado, problemas de relacionamento com colegas/agressão física ou psicológica/bullying/preconceito, problemas de relacionamento com os professores ou colaboradores da escola/agressões físicas ou psicológicas, problemas de relacionamento familiar (separação dos pais/brigas frequentes, etc.).

No gráfico 2, os motivos categorizados como "outros" também dizem respeito àqueles observados em menor proporção. Entretanto, foram observados alguns motivos diversos dos anteriores. Além daqueles apontados no gráfico 1, ocorreram casos envolvendo dificuldades de aprendizagem acumuladas ao longo da vida escolar, gravidez na adolescência/parto recente, mudança de unidade escolar ou endereço com confirmação de estar estudando, suspeita de abuso/exploração sexual, suspeita de possível envolvimento com o uso de drogas/dependência química/tratamento toxicológico e viagem temporária com a família.

As medidas adotadas variam conforme a natureza do caso. No ano de 2019, de acordo com as estatísticas do programa APOIA, a principal medida utilizada foi a advertência aos pais, adotada pelo MP em $32,1 \%$ dos casos em Monte Castelo e $43,5 \%$ das ocorrências em Papanduva. Nestes casos é efetuado o acordo com os genitores para promover a matrícula dos filhos e acompanhar a frequência escolar devendo apresentar na sequência comprovante hábil ao parquet, atestando a matrícula ou a continuidade da frequência escolar do discente ausente na rede de ensino.

A orientação, apoio e acompanhamento do estudante pelo próprio MP foi medida necessária em 32,1\% dos casos em Monte Castelo e 30,4\% dos casos em Papanduva. Nas demais ocorrências, em ambas as cidades, foram adotadas diversas medidas inerentes aos casos, não cadastradas no sistema, abrangendo encaminhamentos à tratamentos ou atendimentos específicos, ou ainda o ajuizamento de ação pleiteando medidas protetivas e/ou representação por infração administrativa decorrente dos deveres inerentes ao poder familiar. Em relação à esta última medida, conforme dados disponibilizados, extrai-se que foram ajuizadas 25 ações na Comarca de Papanduva, não sendo relatado em quantos destes casos o discente atingiu a maioridade (sendo caso apenas de representação por infração administrativa). 
Neste contexto, através das medidas supracitadas, o panorama geral das atividades do Ministério Público na Comarca de Papanduva durante o ano de 2019, através do programa APOIA, é a seguinte:

Tabela 1 - Panorama geral das ocorrências na Comarca de Papanduva em 2019

\begin{tabular}{c|c|c|c}
\hline Ocorrência & Monte Castelo & Papanduva & Total Comarca \\
\hline Total & 95 & 128 & 223 \\
Exito & 71 & 107 & 178 \\
Alunos com APOIA & 70 & 91 & 161 \\
Alunos que voltaram & 51 & 76 & 127 \\
APOIA em atraso no final do & 2 & 7 & 9 \\
ano & 2 &
\end{tabular}

Fonte: Dados da pesquisa, 2019.

Analisando os dados em tela, denota-se que dos 223 casos ocorridos na Comarca, 178 deles foram resolvidos com êxito até o final de 2019. Dos 161 alunos atendidos, 127 voltaram a estudar, havendo 9 procedimentos em atraso, isto é, que não foram resolvidos até o final do ano de 2019. Acerca destes casos em atraso, os motivos podem variar, desde o fato de terem sido instaurados próximos ao final do ano até a complexidade do caso - demandando mais tempo para solução.

A diferença entre o número total de ocorrências e o número total de alunos com APOIA ocorre devido ao fato de que determinados alunos geram mais de uma ocorrência por ano, sendo contumaz a ausência do discente na rede escolar.

Em uma análise percentual comparativa entre o número total de casos ocorridos na Comarca e o número de casos resolvidos com êxito, $79,82 \%$ dos procedimentos foram concluídos com sucesso. Entretanto, necessário analisar com cautela tal ponto e atentar ao fato de que a diferença entre tais variáveis abrange os casos em que a maioridade foi atingida ou o procedimento foi arquivado devido à judicialização do caso.

Nesta perspectiva, a análise comparativa entre o total de alunos com ocorrência no sistema APOIA e o total de alunos que retornaram aos estudos exsurge como mais adequada para indicar a taxa de sucesso do programa no contexto do efetivo retorno aos estudos. Desta maneira, aferindo as variáveis em comento, verifica-se que a taxa de alunos que voltaram às escolas da Comarca através da atuação do programa foi de $78,8 \%$. 


\section{CONCLUSÃO}

Preambularmente a presente pesquisa possibilitou a análise do direito fundamental da educação como essencial ao desenvolvimento pessoal, econômico e social, sendo que a legislação brasileira, através principalmente da Constituição Federal, do Estatuto da Criança e do Adolescente e da Lei de Diretrizes e Bases da Educação, possui amplo arcabouço de normas reguladoras e protetivas, tendo o Ministério Público como guardião da efetiva aplicabilidade delas.

Tal premissa foi vislumbrada através da atuação do parquet em 2019 na Comarca de Papanduva, em seu combate ao absenteísmo escolar através do programa APOIA, conforme análise dos dados estatísticos fornecidos Centro de Apoio Operacional da Infância e Juventude do Ministério Público de Santa Catarina.

Isto porque a pesquisa demonstrou que o programa APOIA, principal mecanismo utilizando pelo parquet para casos desta natureza, contemplou diversos ângulos da problemática do absenteísmo discente, possibilitando a análise do cerne do problema. É dizer, a premissa de investigar o motivo, visto que a ausência do aluno pode demonstrar vários problemas mais graves, para utilizar a medida mais eficiente e adequada aos casos específicos amplia a probabilidade de êxito em promover a solução do caso e assegurar que o aluno retorne aos estudos. Tal assertiva pode ser verificada através da análise dos dados supramencionados, os quais demonstraram a preocupação pela identificação dos motivos bem como diversidade das medidas empregadas.

Extrai-se dos dados, primeiramente em relação ao número total de ocorrências no contexto paradigma, que embora a população estimada no município de Papanduva configurasse mais que o dobro que a estimada em Monte Castelo na época, tal proporção não foi inteiramente refletida no total de ocorrências do programa.

Tendo em vista tratar de cidades pequenas e vizinhas, possível melhor observação, controle e atuação nestes casos, bem como atuação conjunta e desenvolvimento de programas e políticas em parceria, a fim de maximizar a eficiência e êxito do APOIA. 
Já em relação aos motivos elencados, desponta o fato de que o principal problema que desencadeou a ausência dos discentes foi a própria resistência deles e o fato não consideraram a escola atrativa ou útil.

Desta forma, o investimento em ações e políticas públicas que ressaltem a importância dos estudos e promovam o desenvolvimento da atração do aluno pelos estudos exsurge como caminho para reduzir o absenteísmo discente. Exemplo disto é a medida de orientação, apoio e acompanhamento do estudante pelo próprio Ministério Público, que acabou sendo uma das principais formas de solução de caso.

Por outro lado, denota-se que o desenvolvimento de metodologias de ensino mais atraentes é necessário, mas o acompanhamento da visão que o jovem possui acerca dos estudos e de seu futuro é essencial, pela família e demais órgãos envolvidos.

Outro ponto que merece destaque é o acompanhamento do aluno que retorna aos estudos, sobretudo nos casos em que sua ausência foi motivada por sua resistência e por não considerarem a escola atrativa ou útil. Logo, merecem acompanhamento para que, além de retornarem, desenvolvam gosto e interesse pelos estudos e vida escolar, sendo necessário o emprego de medidas que façam o discente perceber a importância da educação para seu desenvolvimento e vida.

A desídia da família em fiscalizar e incentivar os discentes à vida escolar também constituiu forte motivo para ausência do aluno no contexto estudado. Tendo em vista a influência familiar na motivação do aluno, a orientação às famílias e sua inclusão nas discussões acerca dos problemas pode auxiliar reduzindo casos e prevenindo o fenômeno em tela.

Acerca dos casos em que o trabalho foi o motivo para a ausência do aluno, possível a implementação de políticas públicas para conciliação de trabalho e estudo, seja pela criação de mais vagas para menor aprendiz, estágios e turnos adaptados para os horários e trabalho em meio período.

A sistemática utilizada ao atribuir a atuação conjunta e escalonada dos órgãos da rede de proteção potencializou a atuação destes, possibilitando o trabalho dos casos por diversas perspectivas. Desta forma, possível que determinado órgão vislumbre situações que os demais não verificaram, ou ainda reafirmar pontos já observados, considerando as múltiplas abordagens. 
A afirmação das escolas e dos Conselhos Tutelares acerca dos casos em que vislumbraram o desinteresse do aluno como motivo amostra tal fato. O trabalho em equipe e uma boa comunicação entre os envolvidos é essencial, portanto, para atingir o objetivo do programa e promover o retorno do discente aos estudos.

Em um panorama geral, considerando que $79,82 \%$ dos casos foram concluídos com êxito e $78,8 \%$ dos alunos voltaram aos estudos, possível afirmar que houve eficácia no combate ao absenteísmo discente. O resultado é positivo em comparação aos casos em que não foi possível, através da sistemática do programa, promover o retorno de alguns alunos.

Entretanto, considerando a existência de casos em que não se obteve êxito em promover o retorno do discente aos estudos, bem como a dinâmica e singularidade dos casos, também é necessário o constante aprimoramento do programa, bem como capacitação dos agentes envolvidos, seja nas especifidades supracitadas ou de maneira geral, da organização e sistemática empregada.

Neste sentido, também é possível a implementação do programa para aumentar sua eficiência a longo prazo através de viés preventivo, como por exemplo com a adoção de medidas além do tratamento individual dos casos, isto é, medidas coletivas.

O programa permite diagnóstico dos principais motivos do absenteísmo na comarca, através de discussão conjunta da rede de proteção e demais órgãos relacionados à educação, como Associações de Pais e Professores, possível o desenvolvimento de planos de ações e ideias de políticas públicas voltadas especificamente para os motivos vislumbrados.

Em relação aos objetivos específicos buscados pela presente pesquisa, logrouse êxito com a análise da natureza do direito fundamental à educação, seus principais reflexos e dispositivos na legislação pátria voltados à sua tutela. Também foi possível examinar as diretrizes do Ministério Público como guardião do direito em comento, o modus operandi utilizado pela instituição nos casos envolvendo absenteísmo discente, o funcionamento do programa APOIA e os principais motivos para a ausência dos alunos no contexto demarcado, culminando na consecução do objetivo geral do estudo em tela.

Sendo assim, os resultados obtidos na presente pesquisa permitem a conclusão de que o Ministério Público atuou na Comarca de Papanduva de forma 
eficaz no combate ao absenteísmo discente durante o ano de 2019, obtendo resultados positivos, sendo condizente com os ditames legais que tutelam o direito fundamental à educação, bem como aos preceitos basilares da instituição do parquet.

\section{REFERÊNCIAS}

BAHIA, Flávia. Direito constitucional descomplicando. 3. ed. Recife: Armador, 2017.

BARCELLOS, Ana Paula de. Curso de direito constitucional. Rio de Janeiro: Forense, 2018.

BRASIL. Constituição Federal. Promulgada em 05 de outubro de 1988. Disponível em: < http://www.planalto.gov.br/ccivil_03/constituicao/constituicao.htm >. Acesso em 24 fev. 2020.

Código de Defesa do Consumidor. Lei n. 8.078, de 11 de setembro de 1990. Disponível em: < http://www.planalto.gov.br/ccivil_03/leis//8078.htm >. Acesso em 06 mai. 2020.

. Estatuto da Criança e do Adolescente. Lei Federal n. 8069, de 13 de julho de 1990. Disponível em: < http://www.planalto.gov.br/ccivil_03/leis//8069.htm > Acesso em 24 fev 2020.

Lei Complementar n. 75. Lei complementar n. 7520 de maio de 1993. Disponível em: < http://www.planalto.gov.br/ccivil_03/leis/LCP/Lcp75.htm>. Acesso em 12 maio 2020.

Lei das diretrizes e bases da educação nacional. Lei n. 9.394, 20 de dezembro de 1996. Disponível em:

<http://www.planalto.gov.br/ccivil_03/leis/19394.htm > Acesso em 21 abr 2020.

. Lei Orgânica Nacional do Ministério Público. Lei n. 8.625. 12 de fevereiro de 1993. Disponível em: < http://www.planalto.gov.br/ccivil_03/leis//8625.htm > Acesso em 24 fev 2020.

CASTRO, Jorge Abrahão de. Financiamento e gasto público na educação básica no Brasil: 1995-2005. Educação e Sociedade. Campinas, v. 28, n. 100, n. Esp., p. 857876, out. 2007.

COSTA, Antonio Gomes da. Família e escola. Revista nova escola, n.193; jun./jul. 2006.

CONCEIÇÃO, Lourivaldo de. Curso de direitos fundamentais. Campina Grande: EDUEPB, 2016. 
CRAIDY, Carmem. KAERCHER, Gládis E. Educação Infantil: Pra que te quero? Porto Alegre: Artmed, 2001.

DAL BOSCO, Maria Goretti. Discricionariedade em políticas públicas: um olhar garantista da aplicação da lei de improbidade administrativa. Curitiba: Juruá, 2007.

DIMENSTEIN, Gilberto. O cidadão de papel: a infância, a adolescência e os direitos humanos no Brasil. São Paulo: Ática, 2005.

GOERCZEVSKI, Clovis. Direitos humanos educação e cidadania: conhecer educar e praticar. Santa Cruz do Sul: EDUNISC, 2009.

GOULART, Marcelo Pedroso. Ministério Público e democracia. Leme, 1987.

ISHIDA, Válter Kenji. Estatuto da Criança e do Adolescente: doutrina e Jurisprudência. 16. ed. São Paulo: Atlas, 2015.

INSTITUTO BRASILEIRO DE GEOGRAFIA E ESTATÍSTICA (IBGE). Cidade de Monte Castelo. Disponível em: < https://cidades.ibge.gov.br/brasil/sc/montecastelo/panorama > Acesso em 22 jun 2020.

INSTITUTO BRASILEIRO DE GEOGRAFIA E ESTATÍSTICA (IBGE). Cidade de Papanduva. Disponível em: <https://cidades.ibge.gov.br/brasil/sc/papanduva/ panorama> Acesso em 22 jun 2020.

INSTITUTO BRASILEIRO DE GEOGRAFIA E ESTATÍSTICA (IBGE). Síntese de Indicadores Sociais - Uma análise das condições de vida - 2019. Disponível em: $<$ https://biblioteca.ibge.gov.br/visualizacao/livros/liv101678.pdf > Acesso em 26 jun 2020.

LIBERATI, Wilson Donizeti. Comentários ao estatuto da criança e do adolescente. 11.ed. São Paulo: Malheiros, 2010

Conteúdo material do direito à educação escolar. Direito à educação: uma questão de justiça. São Paulo. Malheiros, 2004

MACIEL, Kátia Regina Ferreira Lobo Andrade (coordenação) et al. Curso de direito da criança e do adolescente: aspectos teóricos e práticos. 11.ed. São Paulo: Saraiva, 2018.

MARTINS JUNIOR, Wallace Paiva. Ministério Público: a constituição e as leis orgânicas. São Paulo. Atlas, 2015. Recurso eletrônico

MAZZILLI, Hugo Nigro. A defesa dos interesses difusos em juízo: meio ambiente, consumidor, patrimônio cultural, patrimônio público e outros interesses. 18. ed. São Paulo: Saraiva, 2005.

MENDES, Gilmar Ferreira. Direitos fundamentais e controle de constitucionalidade. São Paulo, Celso Bastos Editor, 1999. 
NUNES, Antônio Carlos Ozório. O Ministério Público e algumas contribuições possíveis à qualidade da educação. In: Ministério Público de São Paulo.

Disponível em: <http://www.mpsp.mp.br/portal/page/portal/Educacao/ qualidade_da_educacao/textos_qualidade_da_educacao/O_Minist\%C3\%A9rio_P\%C 3\%BAblico_e_alguma_contribui\%C3\%A7\%C3\%B5es_poss\%C3\%ADveis_\%C3\%A0 _qualidade_da_educa\%C3\%A7\%C3\%A3o.pdf > Acesso em 12 jun. 2020.

PADILHA, Rodrigo. Direito constitucional. 5.ed. rev., atual. e ampl. Rio de Janeiro: Forense, São Paulo: Método, 2018.

SANTA CATARINA. Ministério Público. Programa de Combate à Evasão Escolar APOIA. Disponível em: <https://www.mpsc.mp.br/programas/programa-de-combatea-evasao-escolar-apoia.> Acesso em: 23 mar. 2020

SANTA CATARINA. Ministério Público. Promotorias de Justiça. Disponível em: $<$ https://www.mpsc.mp.br/promotorias-de-justica/encontre-uma-promotoria> Acesso em: 23 mar. 2020

SANTA CATARINA. Tribunal de Justiça. Comarca de Papanduva. Disponível em: <https://www.tjsc.jus.br/comarcas/papanduva >. Acesso em: 22 jun 2020.

VASCONCELLOS, Suziane Santana de; MATTOS, Carmem Lúcia Guimarães de. O absenteísmo escolar e sua regulamentação. In: Etnografia e educação: conceitos e usos. Campina Grande: EDUEPB, 2011.

Artigo recebido em: 30/08/2020

Artigo aceito em: 29/10/2020

Artigo publicado em: 27/04/2021 